\title{
HYPOMAGNESAEMIA DUE TO LEAD POISONING IN THE CONTEXT OF A HETEROZYGOUS CLDN-16 VARIANT
}

Priya Ramaswamy ${ }^{1}$, Malathi Kurre ${ }^{1}$, Dominik Muller ${ }^{2}$, Paul Dargan $^{3}$, Evelien Gevers ${ }^{1}$, Jeremy Allgrove ${ }^{1}$

${ }^{1}$ Barts Health NHS Trust, London, UK ; ${ }^{2}$ Charite Department of Paediatric Nephrology, Berlin, Germany;

${ }^{3}$ Guy's and St Thomas' NHS Foundation Trust, London, UK

\section{INTRODUCTION}

- Although toxic to many tissues, lead poisoning has not previously been reported to cause excessive urinary magnesium loss. Hypomagnesaemia may cause acquired hypoparathyroidism by impairing parathyroid hormone secretion.

- Claudin proteins refer to a family of structurally related proteins which are involved in the formation of tight junctions in various tissues.

- We present the case of a child who developed hypermagnesuria and hypomagnesaemia with secondary hypoparathyroidism caused by lead poisoning in the context of a heterozygous variant in CLDN16 gene.

\section{CASE STUDY}

- Three year old boy

- Third born child of healthy, non consanguineous parents

- Presented with carpopedal spasms of hands and feet

- Background history of pica and autism

- Hypocalcaemia and severe hypomagnesaemia present

Urinary loss of magnesium and calcium present

\section{COURSE AND MANAGEMENT}

- Received multiple iv calcium and magnesium boluses

Started on oral calcium, magnesium and colecalciferol

Hypocalcaemia resolved within a few days

However, hypomagnesaemia was severe and persistent

- Renal magnesium losses continued

- Started on continuous iv magnesium infusion

- Plasma lead concentrations were extremely high $(4.3 \mu \mathrm{mol} / \mathrm{l})$

- Received chelation with Dimercaptosuccinic acid (DMSA)

Lead concentrations decreased $(1.7 \mu \mathrm{mol} / \mathrm{l})$ in one month

Oral magnesium weaned and stopped after 10 weeks

Lead levels increased again one year later $(2.62 \mu \mathrm{mol} / \mathrm{l})$, due to remobilisation of lead from bone stores and repeat chelation with DMSA given (third course). Interestingly, magnesium levels dropped $(0.65 \mathrm{mmol} / \mathrm{l})$ when lead levels increased. Magnesium levels normalised on oral magnesium replacement.
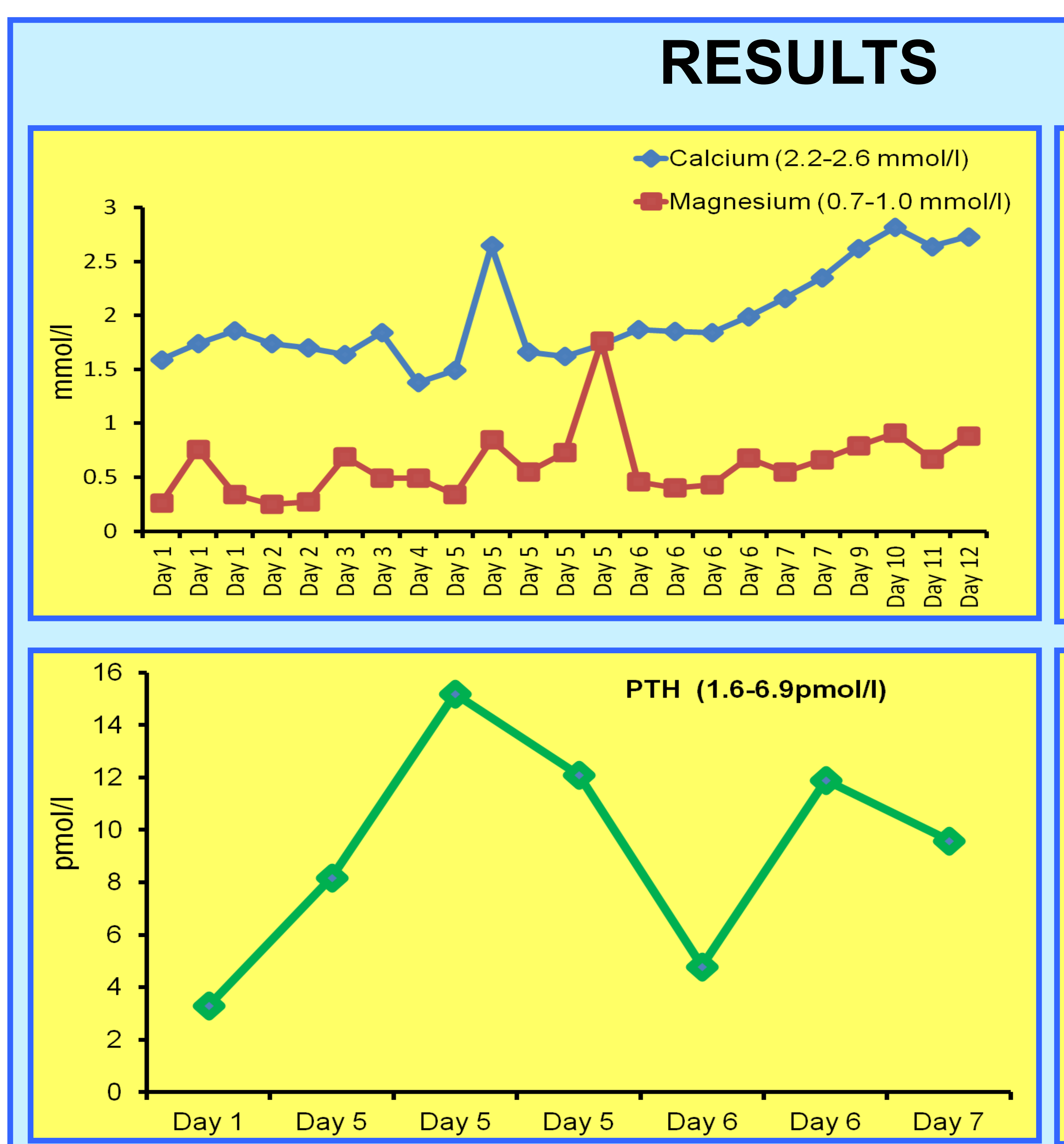

Parathyroid hormone (PTH) concentrations were initially inappropriately low and normalised when treated with magnesium

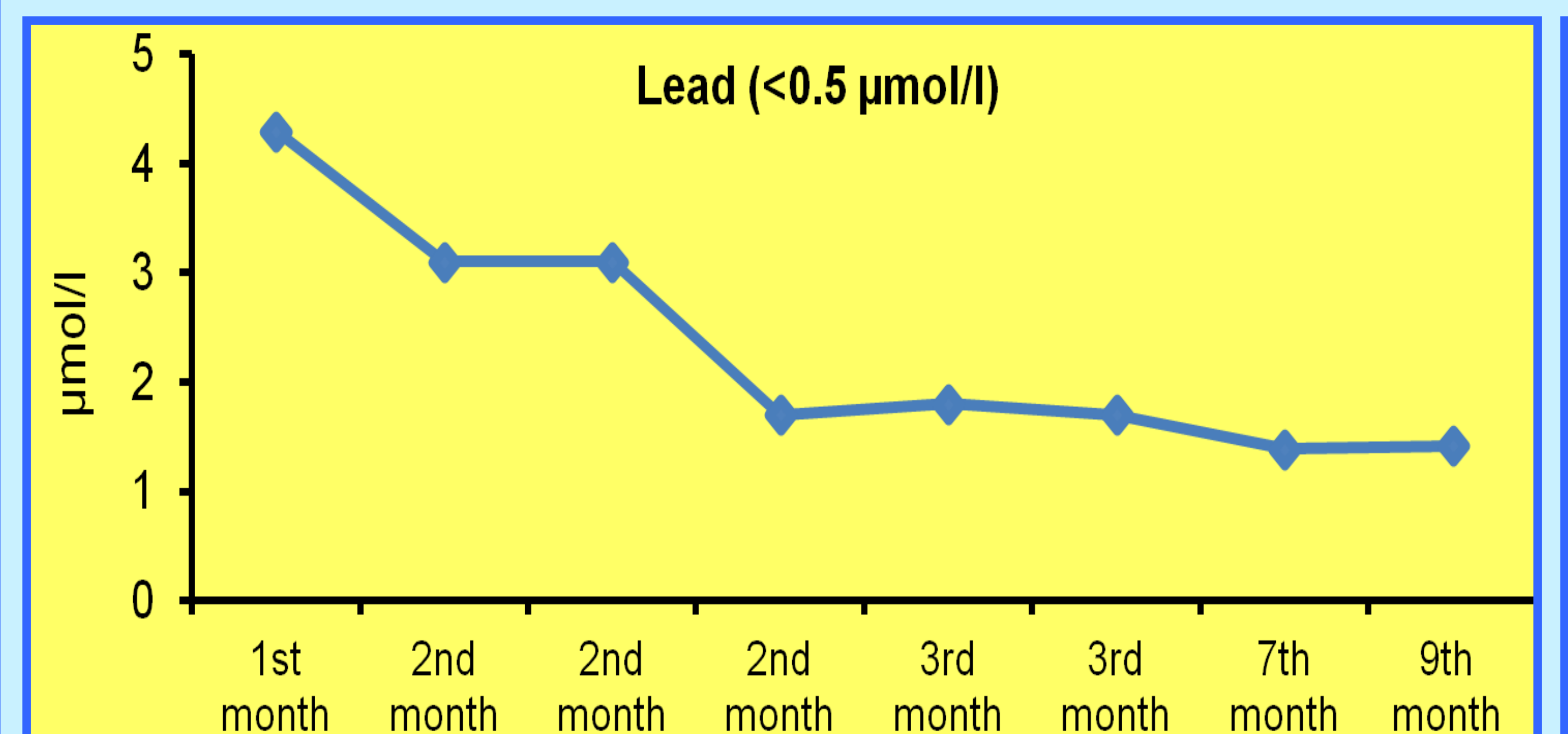

Lead levels were extremely high $(4.3 \mu \mathrm{mol} / \mathrm{l})$ and decreased after chelation with oral DMSA (two courses given)

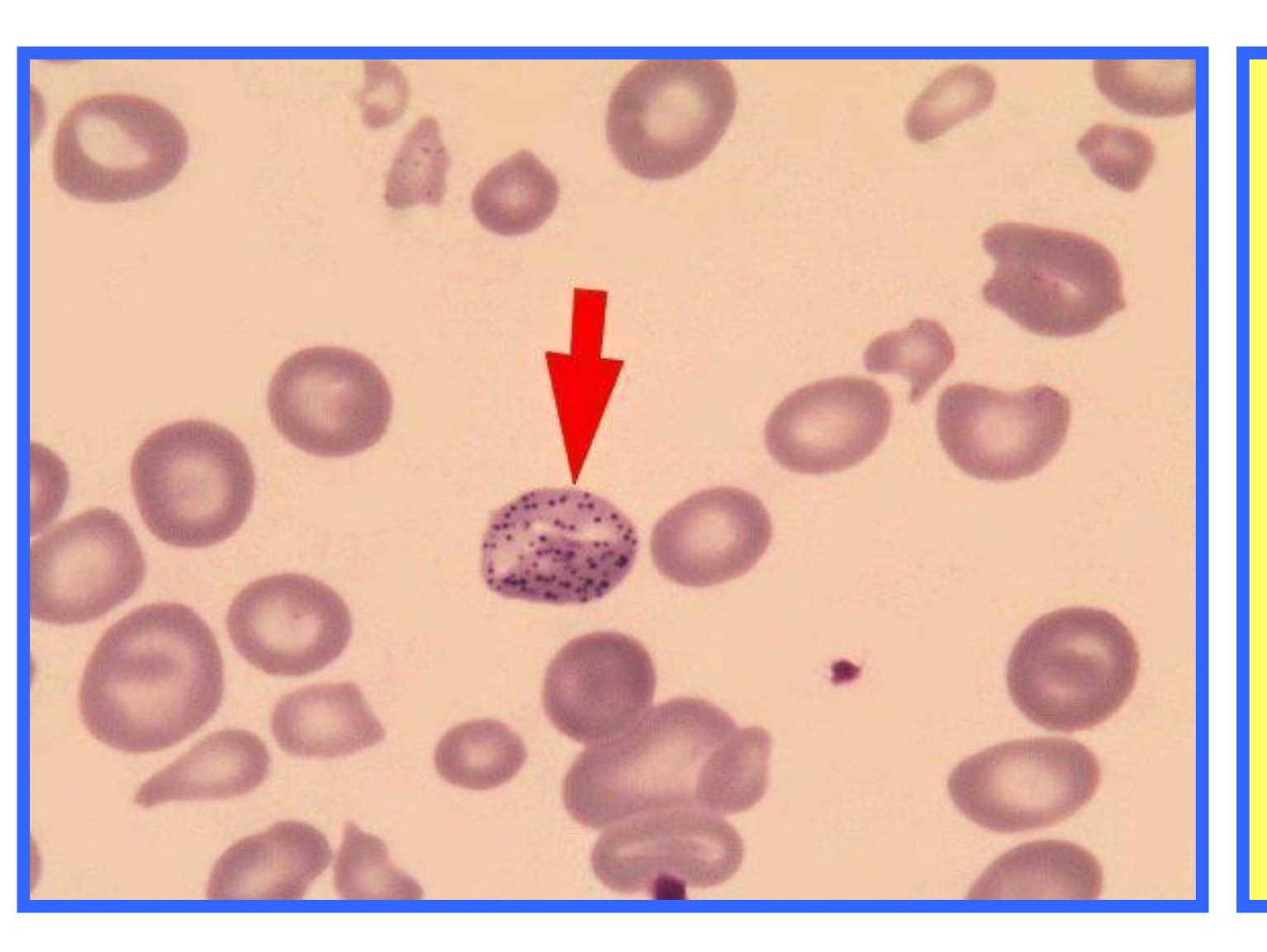

Blood film revealed basophilic stippling of red blood cells, which suggested lead poisoning. Opinion from Toxicology was urgently obtained, who suggested chelation with oral DMSA.

Public Health England was notified.

Family members were screened and negative.

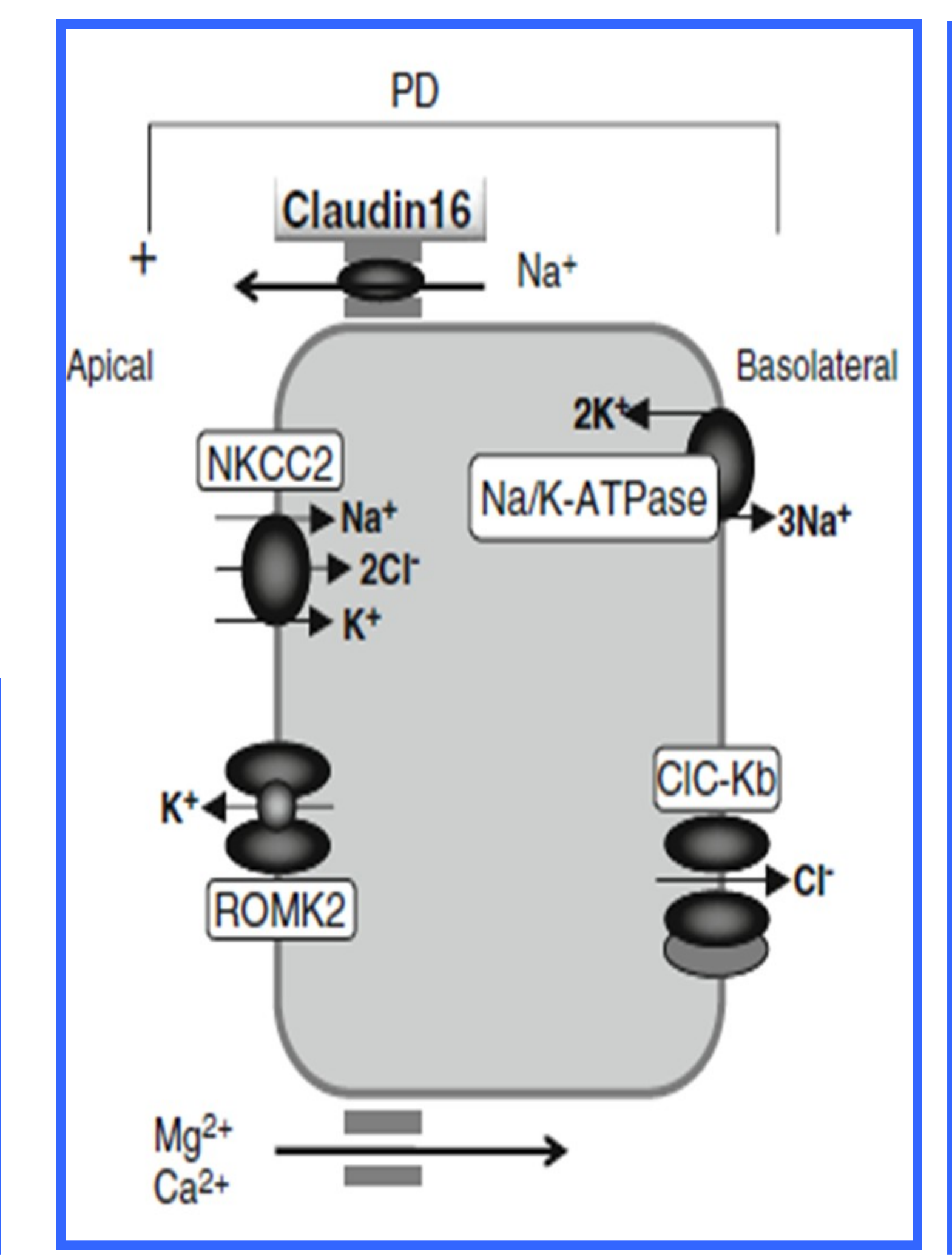

Genetic studies to assess known genetic causes of hypomagnesaemia revealed heterozygous variant in CLDN16 gene which encodes claudin-16, an important tight junction protein expressed in Henle's loop and distal tubule of the kidney.

Homozygous mutations in CLDN16 gene causes familial hypomagnesaemia with hypercalciuria and nephrocalcinosis (FHHNC), but heterozygotes are usually asymptomatic.

\section{DISCUSSION}

Familial hypomagnesaemia with hypercalciuria and nephrocalcinosis (FHHNC) is an autosomal recessive condition that is caused by homozygous mutations in the CLDN16 gene. FHHNC is characterised by excessive renal magnesium and calcium loss, persistent hypomagnesaemia, nephrocalcinosis and renal failure. The overall prognosis is poor, and definitive cure is by renal transplantation.

It is known that lead poisoning causes toxic effects to all organs, including the kidney, although magnesium loss has not been previously described in humans. In young rats, competitive antagonism between lead, calcium and magnesium has been shown in experimental studies. We suggest that, in our patient, lead poisoning resulted in hypermagnesuria in the context of a heterozygous CLDN16 variant. 